\title{
Diabetic retinal neuropathy revisited. A perspective after optical coherence tomography angiography
}

\author{
Selma A Somilleda-Ventura ${ }^{1}$, Dulce M Razo Blanco-Hernández ${ }^{2}$ and Virgilio Lima-Gómez ${ }^{3 *}$ \\ ${ }^{1}$ Research Direction, Hospital Juárez de México, CDMX, México \\ ${ }^{2}$ Research Division, Hospital Juárez de México, CDMX, México \\ ${ }^{3}$ Ophthalmology service, Hospital Juárez de México, CDMX, México
}

\begin{abstract}
Diabetic retinal neuropathy is a disorder that can appear before clinical signs of diabetic retinopathy; the evidence of neuronal damage has been reported in histologic and experimental studies in subjects with diabetic retinopathy. Signs of early dysfunction can be identified using functional tests such as retinal sensitivity, contrast sensitivity, color vision and electroretinogram, all of which show changes in diabetic subjects without retinopathy compared with non-diabetic subjects. Optical coherence tomography has identified a thinning of the ganglion cell layer in diabetic subjects without retinopathy, which has been considered a surrogate of early neuronal damage, and has been proposed to develop before retinal vascular damage. Optical coherence tomography angiography is now able to identify vascular density and perfusion, which also appear before retinopathy in diabetic subjects. Diabetic retinal neuropathy could again be linked to vascular impairment, and the evaluation of the retinal neurovascular unit will require simultaneous measurement of parafoveal density and functional tests to identify the early interactions of microvascular and neuronal retinal damage.
\end{abstract}

\section{Introduction}

Diabetic retinopathy (DR) is a chronic and specific complication of diabetes, which represents the leading cause of blindness in productive age worldwide [1,2]. Classically, it is considered a microvascular disease, although retinal damage has a component of neural dysfunction, which can occur from stages prior to the appearance of clinical vascular changes in the retina and has been called retinal diabetic neuropathy (RDN) [3].

Changes in the neural tissue of the retina affect both neurons and glia and can be identified by measuring their function with tests such as electroretinogram, color vision (CV), contrast sensitivity (CS), and retinal sensitivity (RS) [4]. Although DR eventually causes visual loss due to neural damage [5], visual acuity (VA) is usually good even in the first stages of DR [6], except when there is macular edema; in patients with diabetes without retinopathy who have no other diseases, VA is usually normal [7].

\section{Early microvascular changes}

In contrast with neural tissue, the retinal capillaries do not have a function that can be measured directly and detecting the damage to these structures requires an anatomical change [8]. Histologically, the first change found in the retinal capillaries is basement membrane thickening [9], which cannot be measured in vivo; subsequently, pericyte loss appears [10]. When the amount of these supporting cells of the retinal capillary network, which are part of the inner hemato-retinal barrier [11], decreases considerably, the weakened capillaries bulge to form a microaneurysm [12], the first ophthalmoscopic manifestation of DR.

The presence of microaneurysms indicates a structural damage to the capillary network [9], and its detection also depends on the magnification with which the retina is evaluated. The resolution power of the direct ophthalmoscope is 60 microns $(\mu \mathrm{m})$, below which smaller microaneurysms cannot be detected. This explains why clinically undetected lesions can be identified in high resolution digital photographs, or using retinal fluorescein, in which the leakage of contrast medium from some small microaneurysms allows to find them. An amount of pericyte loss that is not enough to allow the formation of a microaneurysm cannot be detected in vivo, and this vascular damage may exist without clinical or fluorescein angiography signs [10]. Another structural change that is reported histologically is the existence of "acellular" capillaries $[13,14]$, which cannot either be detected by fluorescein angiography, or modify the diameter of the foveal avascular zone, the standard for identifying damage to the capillary network in the macula by this study.

Fluorescein angiography can also reveal areas in which the contrast medium does not appear, which correspond to regions of capillary closure [15], but they appear after the clinical signs of retinopathy. Besides the mentioned findings, the traditional evaluation did not have other elements to measure the anatomical changes in the capillary plexuses of the retina before diabetic retinopathy appeared.

*Correspondence to: Virgilio Lima Gómez, Hospital Juárez de México, Av. Instituto Politécnico Nacional 5160, Magdalena de las Salinas, C.P. 06770, Gustavo A. Madero, Mexico City, Mexico, Tel: (52) 55 57477624; E-mail: forscher7@gmail.com

Key words: diabetic retinal neuropathy, ganglion cells, optical coherence tomography angiography, vascular density

Received: December 03, 2018; Accepted: December 12, 2018; Published: December 17, 2018 


\section{Early neural changes}

Neural damage is a characteristic of diabetic retinopathy [16] and is found both in experimental models and post-mortem studies. The dysfunction of the retinal neurons can be measured before anatomical changes [17]. Thus, in subjects with diabetes who do not have retinopathy it has been reported that RS, the ability to distinguish a stimulus on a previously illuminated background, was lower than in non-diabetic subjects; although this reduction was not statistical, it shifted the points of maximum sensitivity outwards to lie in a paracentral area, which attenuated the perception of light stimuli up to $35 \%$ [18]. The decrease in CS is also related to the presence of $\mathrm{RDN}$, the duration of diabetes and age [19], even without visual acuity impairment. Gella et al. [20] found a positive correlation between CS and glycated hemoglobin, which they attributed to vascular changes caused by hypoxia in the retina, and to the relationship that it has with cells of the neural axis [21]. Additionally, color vision tests show that a blue-yellow dysfunction exists in subjects with diabetes without DR, ranging from $21.5 \%$ [22] to $74.6 \%$ [23], even when VA is $20 / 40$.

All these changes indicate an alteration in the neural function of the retina, which precedes the microvascular changes detectable clinically and by fluorescein angiography. It has been proposed that they may reflect a neurodegeneration, due to the association with the late changes of the retinal neurons that occur when diabetic retinopathy already exists; [24] however, a definite anatomical change in neural tissue in vivo has not been reported, before clinical microvascular changes of retinopathy appear.

\section{Optical coherence tomography}

A diagnostic tool that modified the approach to retinal diseases is optical coherence tomography (OCT). This study uses the principle of low coherence interferometry to generate images of the retina [25], which allows obtaining anatomical sections with a similar quality of optical microscopy, without fixation artifacts. Current devices of spectral domain have a $3 \mu \mathrm{m}$ resolution [26] and allow to distinguish and measure the layers of the retina; consequently, the layers where neurons exist can be measured selectively, and these measurements could aid in estimating whether there is diabetes-related neural tissue loss, before clinical retinopathy occurs.

Spectral domain OCT devices measures the nerve fiber layer, and some have been used to measure the ganglion cell layer (GCL) and the inner plexiform layer simultaneously [27]. The most recent software allows the selective measurement of GCL, which features damage in histological studies of patients with DR; $[28,29]$ with the current OCT resolution, this layer is the object of studies that seek to determine whether a reduction of its thickness could work as a surrogate variable of structural neuronal damage.

It has been identified that the GCL thickness decreases in subjects with diabetes without retinopathy [30], with respect to subjects without diabetes; the foveal avascular zone (FAZ) has been used as a control variable, because it was assumed that that its normal features could exclude preclinical microvascular damage. That anatomical change, by itself, would support the functional data of RDN and suggest that the neural damage appears before there is vascular damage.

\section{Optic coherence tomography angiography (OCTA)}

An additional instrument provided by the most recent OCT devices is angiography. It has the advantage over fluorescein angiography that its higher resolution allows to identify the capillaries $[31,32]$ and thus quantify vascular density in the superficial and deep plexuses of the retina [33]. Although it does not allow the detection of capillary leakage, which is relevant for subjects with retinopathy, this feature may not be necessary to evaluate early damage to the capillary network in subjects without retinopathy.

It has been identified that the parafoveal vessel density decreases in subjects with diabetes without retinopathy, with respect to subjects without diabetes $[34,35]$. This change appears without altering the size of the FAZ [36] and it represents the earliest of diabetes induced microvascular damage, which can be measured with current diagnostic tests.

\section{Ganglion cell layer thickness and vascular density}

Identifying the reduction of parafoveal vascular density could change the concept of neural damage prior to the appearance of vascular damage, in the subject with diabetes without retinopathy. Although vascular density is also an anatomical variable, its reduction could cause early neuronal dysfunction, even when there is no structural damage to the ganglion cells.

The evaluation of the macula seems an appropriate model for evaluating GCL thickness, because this region contains $40 \%$ of those neurons [37] and a decrease would be easier to identify there [38]. However, a reduction in the thickness of this layer should be selective to represent structural damage: this change could be accompanied by a reduction in the thickness of the entire macula, or be caused by another diseases, such as glaucoma [39-42].

The retinal thickness decreases in subjects with diabetes without retinopathy, which could be the result of a reduced capillary density. About $20 \%$ of the weight of the retina belongs to vascular tissue, and the reduction of capillaries before the onset of clinical retinopathy could explain a reduction in retinal thickness; this reduction in thickness may not be evident when retinopathy appears, if the decreased capillary density led to hypoxia, and activated cytokines such as vascular endothelial growth factor, which enlarge the retinal thickness by increasing vascular permeability.

The increase in capillary permeability does not necessarily lead to macular edema: this condition occurs when the amount of fluid that leaks from the capillaries exceeds the ability of the retinal pigment epithelium to remove it [43]. Once retinopathy begins, a subtle capillary leakage could compensate the reduction in retinal thickness that occurs before clinical changes appear and return the retinal thickness to a normal value.

An indirect data of hypoxia could be capillary perfusion, which can also be measured by coherence tomography angiography; its correlation with parafoveal capillary density should theoretically be high, but it still requires to be determined.

Similarly, the GCL thickness could decrease when parafoveal vessel density does; the thickness of this layer could vary according to the health of vascular tissue, as a result of its contiguity of the nerve fiber layer, along which the superficial capillary plexus runs. Consequently, attributing a reduction of the GCL thickness to neuronal loss of neurons would require determining whether it is unrelated to the reduction of total retinal thickness.

Bearing this in mind, the reduction of parafoveal vessel density would be an anatomical vascular change that could occur before of retinal neuron dysfunction; the reduction of perfusion could explain alterations in retinal sensitivity, color vision, contrast sensitivity and 
increased latency in the electroretinogram because of hypoxia, even without neuronal body loss.

A study that compared subjects without diabetes and subjects with diabetes with no retinopathy, which did not include subjects with glaucoma, identified a reduction of parafoveal vessel density in the second group, without changes of GCL thickness. It is still necessary to determine the level of macular perfusion that induces a thinning of the retina, and the level at which changes in neural function occur [44]. Vujosevic et al. [45] found as well that the difference of inner retinal layer thickness was not statistically different between non-diabetic and type 1 diabetic subjects, although capillary loss was more common in the second group.

\section{Conclusion}

Diabetic retinal neuropathy is a change that can occur before clinical changes of diabetic retinopathy appear, and it might be caused by poor perfusion, resulting from a decreased parafoveal capillary density. The evaluation of the patient with diabetes without retinopathy should combine neuronal function tests and the information of optical coherence tomography angiography, in order to determine the sequence of early damage in the neurovascular unit of the retina and define strategies to manage it and link it with diabetes-induced injuries in other organs.

\section{References}

1. Zheng Y, He M, Congdon N (2012) The worldwide epidemic of diabetic retinopathy. Indian J Ophthalmol 60: 428-431. [Crossref]

2. Pearce I, Simo R, Lovestam-Adrian M, Wong DT, Evans M (2018) Association between diabetic eye disease and other complications of diabetes: Implications for care. A systematic review. Diabetes Obes Metab. [Crossref]

3. Adams AJ, Bearse MA Jr. (2012) Retinal neuropathy precedes vasculopathy in diabetes: a function-based opportunity for early treatment intervention?. Clin Exp Optom 95: 256-265. [Crossref]

4. Homme RP, Singh M, Majumder A, George AK, Nair K, et al. (2018) Remodeling of Retinal Architecture in Diabetic Retinopathy: Disruption of Ocular Physiology and Visual Functions by Inflammatory Gene Products and Pyroptosis. Front Physiol. [Crossref]

5. Van Dijk HW, Verbraak FD, Kok PH, Stehouwer M, Garvin MK, et al. (2012) Early neurodegeneration in the retina of type 2 diabetic patients. Invest Ophthalmol Vis Sci 53: 2715-2179. [Crossref]

6. Stem MS, Gardner TW (2013) Neurodegeneration in the pathogenesis of diabetic retinopathy: molecular mechanisms and therapeutic implications. Curr Med Chem 20: 3241-3250. [Crossref]

7. Chen Y, Li J, Yan Y, Shen X (2016) Diabetic macular morphology changes may occur in the early stage of diabetes. BMC Ophthalmol 16: 12. [Crossref]

8. Sohn EH, van Dijk HW, Jiao C, Kok PH, Jeong W, et al. (2016) Retinal neurodegeneration may precede microvascular changes characteristic of diabetic retinopathy in diabetes mellitus. Proc Natl Acad Sci U S A. 113: E2655-2664. [Crossref]

9. Semeraro F, Cancarini A, dell'Omo R, Rezzola S, Romano MR, et al. (2015) Diabetic Retinopathy: Vascular and Inflammatory Disease. J Diabetes Res 2015: 582060. [Crossref]

10. Duh EJ, Sun JK, Stitt AW (2017) Diabetic retinopathy: current understanding, mechanisms, and treatment strategies. JCI Insight. 2: e93751. [Crossref]

11. Arboleda-Velasquez JF, Valdez CN, Marko CK, D'Amore PA (2015) From pathobiology to the targeting of pericytes for the treatment of diabetic retinopathy. Curr Diab Rep 15: 573. [Crossref]

12. Rubsam A, Parikh S, Fort PE (2018) Role of Inflammation in Diabetic Retinopathy. Int J Mol Sci 19. [Crossref]

13. Kern TS, Engerman RL (1995) Vascular lesions in diabetes are distributed nonuniformly within the retina. Exp Eye Res 60: 545-549. [Crossref]
14. Shanab AY, Mysona BA, Matragoon S, El-Remessy AB (2015) Silencing p75(NTR) prevents proNGF-induced endothelial cell death and development of acellular capillaries in rat retina. Mol Ther Methods Clin Dev 2: 15013. [Crossref]

15. Spaide RF, Klancnik JM Jr, Cooney MJ (2015) Retinal vascular layers imaged by fluorescein angiography and optical coherence tomography angiography. JAMA Ophthalmol 133: 45-50. [Crossref]

16. Muc R, Saracen A, Grabska-Liberek I (2018) Associations of Diabetic Retinopathy with Retinal Neurodegeneration on the Background of Diabetes Mellitus. Overview of Recent Medical Studies with an Assessment of the Impact on Healthcare systems. Open Med (Wars) 13: 130-136. [Crossref]

17. Barber AJ (2003) A new view of diabetic retinopathy: a neurodegenerative disease of the eye. Prog Neuropsychopharmacol Biol Psychiatry 27: 283-290. [Crossref]

18. Somilleda-Ventura SA, Ceballos-Reyes GM, Lima-Gómez V (2018) Comparison of macular retinal sensitivity and its contribution to the foveal sensitivity between diabetic and non-diabetic patients with normal visual acuity. J Optom pii: S18884296(18)30082-7. [Crossref]

19. Wolff BE, Bearse MA Jr, Schneck ME, Dhamdhere K, Harrison WW, et al. (2015) Color vision and neuroretinal function in diabetes. Doc Ophthalmol 130: 131-139. [Crossref]

20. Gella L, Raman R, Pal SS, Ganesan S, et al. (2017) Contrast sensitivity and its determinants in people with diabetes: SN-DREAMS-II, Report No 6. Eye (Lond) 31: 460-466. [Crossref]

21. Gebka A, Serkies-Minuth E, Raczynska D (2014) Effect of the administration of alphalipoic acid on contrast sensitivity in patients with type 1 and type 2 diabetes. Mediators Inflamm 2014: 131538. [Crossref]

22. Tan NC, Yip WF, Kallakuri S, Sankari U, Koh YLE (2017) Factors associated with impaired color vision without retinopathy amongst people with type 2 diabetes mellitus: a cross-sectional study. BMC Endocr Disord 17: 29. [Crossref]

23. Gella L, Raman R, Kulothungan V, Pal SS, Ganesan S, et al. (2017) Color vision abnormalities in type II diabetes: Sankara Nethralaya Diabetic Retinopathy Epidemiology and Molecular Genetics Study II report no 2. Indian J Ophthalmol 65 989-994. [Crossref]

24. Tan NC, Yip WF, Kallakuri S, Sankari U, Koh YLE (2017) Factors associated with impaired color vision without retinopathy amongst people with type 2 diabetes mellitus: a cross-sectional study. BMC Endocr Disord 17: 29. [Crossref]

25. Brautaset R, Birkeldh U, Frehr Alstig P, Wikén P, Nilsson M (2016) Repeatability Using Automatic Tracing with Canon OCT- HS100 and Zeiss Cirrus HD-OCT 5000 PLoS One 11: e0149138. [Crossref]

26. Murthy RK, Haji S, Sambhav K, Grover S, Chalam KV (2016) Clinical applications of spectral domain optical coherence tomography in retinal diseases. Biomed J 39: 107 120. [Crossref]

27. Dalgliesh JD, Tariq YM, Burlutsky G, Mitchell P (2015) Symmetry of retinal parameters measured by spectral-domain OCT in normal young adults. $J$ Glaucoma 24: 20-24. [Crossref]

28. Munk MR, Giannakaki-Zimmermann H, Berger L, Huf W, Ebneter A, et al. (2017) OCT-angiography: A qualitative and quantitative comparison of 4 OCT-A devices. PLoS One 12: e0177059. [Crossref]

29. Srinivasan S, Pritchard N, Sampson GP, Edwards K, Vagenas D, et al. (2017) Diagnostic capability of retinal thickness measures in diabetic peripheral neuropathy. J Optom 10: 215-225.

30. Ng DS, Chiang PP, Tan G, Cheung CG, Cheng CY, et al. (2016) Retinal ganglion cell neuronal damage in diabetes and diabetic retinopathy. Clin Exp Ophthalmol 44: 243250. [Crossref]

31. Kashani AH, Chen CL, Gahm JK, Zheng F, Richter GM, et al. (2017) Optical coherence tomography angiography: A comprehensive review of current methods and clinical applications. Prog Retin Eye Res 60: 66-100. [Crossref]

32. Sambhav K, Grover S, Chalam KV (2017) The application of optical coherence tomography angiography in retinal diseases. Surv Ophthalmol 62: 838-866. [Crossref]

33. de Carlo TE, Chin AT, Bonini Filho MA, Adhi M, Branchini L, et al. (2015) Detection of microvascular changes in eyes of patients with diabetes but not clinical diabetic retinopathy using optical coherence tomography angiography. Retina 35: 2364-2370. [Crossref]

34. Dimitrova G, Chihara E, Takahashi H, Amano H, Okazaki K (2017) Quantitative Retinal Optical Coherence Tomography Angiography in Patients with Diabetes Without Diabetic Retinopathy. Invest Ophthalmol Vis Sci 58: 190-196. [Crossref] 
35. Cao D, Yang D, Huang Z, Zeng Y, Wang J, et al. (2018) Optical coherence tomography angiography discerns preclinical diabetic retinopathy in eyes of patients with type 2 diabetes without clinical diabetic retinopathy. Acta Diabetol 55: 469-477. [Crossref]

36. Lima-Gomez V, Razo Blanco-Hernandez DM, Somilleda-Ventura SA (2018) Comparacion de la densidad capilar parafoveal entre sujetos sanos y diabéticos con y sin retinopatia. Gaceta Med Mex 154: S30-S35. [Crossref]

37. Curcio CA, Allen KA (1990) Topography of ganglion cells in human retina. J Comp Neurol 300: 5-25. [Crossref]

38. Smith CA, Vianna JR, Chauhan BC (2017) Assessing retinal ganglion cell damage. Eye (Lond) 31: 209-217. [Crossref]

39. Lee SY, Jeoung JW, Park KH, Kim DM (2015) Macular ganglion cell imaging study: interocular symmetry of ganglion cell-inner plexiform layer thickness in norma healthy eyes. Am J Ophthalmol 159: 315-323. [Crossref]

40. van Dijk HW, Verbraak FD, Kok PH, Garvin MK, Sonka M, et al. (2010) Decreased retinal ganglion cell layer thickness in patients with type 1 diabetes. Invest Ophthalmol Vis Sci 51: 3660-3665. [Crossref]
41. Zhang X, Francis BA, Dastiridou A, Chopra V, Tan O, et al. (2016) Advanced Imaging for Glaucoma Study Group. Longitudinal and cross-sectional analyses of age effects on retinal nerve fiber layer and ganglion cell complex thickness by fourier-domain OCT. Transl Vis Sci Technol 5: 1. [Crossref]

42. Leung CKS, Ye C, Weinreb RN, Yu M, Lai G, et al. (2013) Impact of age-related change of retinal nerve fiber layer and macular thicknesses on evaluation of glaucoma progression. Ophthalmology 120: 2485-2492. [Crossref]

43. Bandello F, Battaglia Parodi M, Lanzetta P, Loewenstein A, Massin P, et al. (2017) Diabetic Macular Edema. Dev Ophthalmol 58: 102-138. [Crossref]

44. Lima V, Razo Blanco DM, Somilleda SA (2018) Distribución del grosor de la capa de células ganglionares en sujetos sin diabetes y sujetos con diabetes con y sin retinopatía. Revista Mexicana de Endocrinología, Metabolismo y Nutrición 5 suppl 1: 35.

45. Vujosevic S, Muraca A, Alkabes M, Villani E, Cavarzeran F, et al. (2017) Early microvascular and neural changes in patients with type 1 and type 2 diabetes mellitus without clinical signs of diabetic retinopathy. Retina. [Crossref]

Copyright: (C2018 Somilleda-Ventura SA. This is an open-access article distributed under the terms of the Creative Commons Attribution License, which permits unrestricted use, distribution, and reproduction in any medium, provided the original author and source are credited. 